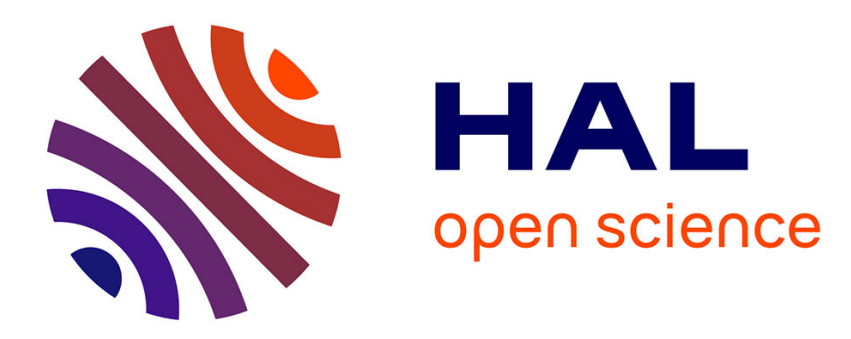

\title{
Application of a dynamic urban model
}

Denise Pumain, Thérèse Saint-Julien, Lena Sanders

\section{To cite this version:}

Denise Pumain, Thérèse Saint-Julien, Lena Sanders. Application of a dynamic urban model. Geographical Analysis, 1987, 1-2, pp.152-168. halshs-01565198

\section{HAL Id: halshs-01565198 \\ https://shs.hal.science/halshs-01565198}

Submitted on 19 Jul 2017

HAL is a multi-disciplinary open access archive for the deposit and dissemination of scientific research documents, whether they are published or not. The documents may come from teaching and research institutions in France or abroad, or from public or private research centers.
L'archive ouverte pluridisciplinaire HAL, est destinée au dépôt et à la diffusion de documents scientifiques de niveau recherche, publiés ou non, émanant des établissements d'enseignement et de recherche français ou étrangers, des laboratoires publics ou privés. 


\title{
Research Notes and Comments
}

\author{
Application of a Dynamic Urban Model \\ by D. Pumain, Th. Saint-Julien, and L. Sanders \\ INTRODUCTION
}

Two different forms of research, castastrophe theory and bifurcation theory, are now followed in designing spatial dynamic models in urban geography. The first explores analytical solutions of mathematical systems involving two or three state variables (Haag and Dendrinos 1983). The second builds larger and more complex models which are able to describe the evolution of an urban structure in a more "realistic" way, but which can only be calibrated by simulations. (Wilson 1981; Allen and Sanglier 1981).

Such dynamic models of urban spatial structure need to be validated in the real world before they can be used operationally. The application in this paper is a small step in the long iterative process between the construction of a model and its use for practical purposes. We examined two questions: what problems are encountered when using models of complex systems to simulate an observed urban evolution and what insight do they provide for comparing the evolution of several cities?

We have used Allen's INTRA URBAN model, in a version already tested on fictitious data (Allen et al. 1981). This is a spatial dynamic model, which simulates the internal evolution of an urban area. As compared with other urban models (see Pumain, Saint-Julien, and Sanders 1984), it has the following properties.

(i) The urban area is viewed as an open system. It is subdivided into many zones, among which employment in economic activities and resident population are in the process of changing and relocating during the same time interval.

(ii) A large number of the theoretical proposals that explain the dynamics of urban areas are put together in the model, as mathematical relations or as parameters. The equations of the model, which will be detailed below, include the economic base principle and distance-decreasing interactions, which were already used in static models such as Lowry's (1964). But they also include principles of location theory like agglomeration economies or crowding effects, which lead to logistic-type growth curves for the development of activities upon a limited space. Other mechanisms are also included, such as competition for space and segregation among different activities and population, unequal speed of adjustment between supply and

We would like to thank P. Allen and M. Sanglier for their help with computer programming and scientific advice during the research. However, we are responsible for any mistakes. This research has been supported by a grant from the CNRS (programme PIREN).

D. Pumain is affiliated with I.N.E.D., Th. Saint-Julien, with Universite Paris I, and L. Sanders, Universite Paris VII.

Geographical Analysis, Vol. 19, No. 2 (April 1987) (C) 1987 Ohio State University Press 
demand, and unequal agreement among location decisions due to differences in the information available to the urban actors.

(iii) The model assumes that general laws apply to a particular spatial combination of population and activities and they determine the largest part of the observed transformations in their intraurban distribution. The driving force of the evolution is a result of the difference between existing and potential occupation of each zone. The potential depends on the relative attractiveness of this zone to the whole urban population and activities, and is constantly under revision, according to internal and external variations.

(iv) Nonlinear differential equations describe for each zone the evolution of each of the six state variables, which will be discussed later. This particular type of equation allows the simulation of qualitative transformations of the spatial structure, for instance, a discontinuity in the centralizing process leading to a decline of the urban center, or to the emergence of one or more secondary centers.

(v) The type of urban dynamics represented by the model involves mechanisms of adjustment between supply and demand at the microlevel in a background of a relatively free competition for space. Interaction processes act unrestrainedly on every point of the urban area being considered. However, space is not considered to be homogeneous for accessibility to the transportation systems, and specific constraints for some places may be the model. This kind of model in then better suited to describe the development of cities where urban planning has not taken too large a role.

For the application we choose four French agglomerations of about the same size and same functional type in the urban hierarchy: Rouen, Bordeaux, Nantes and Strasbourg. We will briefly describe the mathematical formulation of the model 列 other towns.

\section{DESCRIPTION OF THE MODEL}

An urban area is subdivided into $n$ zones. Each zone is characterized by a given number of jobs in four types of activities and two groups of resident population. According to the economic base principle, a distinction is made between exporting activities, whose development rests upon an external demand, and service activities which are induced by the resident population. Each group of activities is then divided according to their different ways of localization in the urban area: among exporting activities are distinguished the secondary (industry) and tertiary (services) activities; induced services are shared out among local services (with a very short range, limited to an urban subarea) and regional services (whose range may be extended to the whole urban agglomeration). As for resident populations, they are divided into two groups: blue-collar and white-collar, differing by their degree of freedom in the choice of the location for their residence.

The equations of the model describe the evolution of one type of employment or of one population group in a zone; they are all of the same form corresponding to a model of spatial growth of the logistic type (Allen and Sanglier 1981):

$$
\frac{d x_{j}}{d t}=\varepsilon\left(1-\frac{x_{j}}{N}\right) x_{j}
$$

where $x_{j}$ is the number of people in zone $j, \varepsilon$ is a parameter describing the speed of adjustment of $x$ to its potential value $N$. This potential varies according to the 
position of zone $j$ in complex interdependencies between populations, activities and zones in the whole city, through a set of parameters. According to the state variable being considered, there are three types of equations: exporting activities, service activities, and the resident population.

\section{Exporting Activities}

The two exporting activities (industry and tertiary) rely upon an exogeneous demand. The potential number of jobs $S_{j}^{E}$ in a zone $j$ depends on this external demand $D^{E}$ and on the relative attractiveness of zone $j\left(A_{j} / \sum A_{j}\right)$ :

$$
\frac{d S_{j}^{E}}{d t}=\varepsilon^{E} S_{j}^{E}\left(1-\frac{S_{j}^{E}}{D^{E} \frac{A_{j}}{\sum_{j} A_{j}}}\right)
$$

where $S_{j}^{E}$ is the number of jobs in activity $E$ in zone $j$, and $\varepsilon^{E}$ is the speed of adjustment of activity $E$ to its potential in any zone. So the potential in a zone is in fact measured by the share of the external demand that this zone is able to attract.

The attractiveness of each zone for this type of activity combines four factors:

(i) Agglomeration and saturation effects. The intensity of already existing activities of type $E$ in one zone $j$ is supposed to attract activities of the same type in a multiplicative way according to a parameter of internal cooperativity $\rho^{E}$ and with another parameter $\psi^{E}$ standing for saturation effects, in the form:

$$
1+\rho^{E} S_{j}^{E}\left(1-\psi^{E} S_{j}^{E}\right)
$$

(ii) Accessibility. A global measure of accessibility (combining historical and geographical factors) is given by a parameter $\alpha_{j}^{E}$, which is the only one in the model to be defined for each zone. It enters into the expression

$$
1 /\left(1+\alpha_{j}^{E} \phi^{E}\right)
$$

where $\phi^{E}$ is the sensitivity of entrepreneurs to accessibility (the lower $\alpha_{j}^{E}$ is, the better the accessibility of zone $j$ ).

(iii) Availability of space. The availability of space acts as a constraint on the location of the activities in the agglomeration. The effects of this constraint are measured by the function

$$
\frac{\tau^{E}}{\tau^{E}+\sum_{k} \gamma^{k} x_{j}^{k}+\sum_{l} \gamma^{l} S_{j}^{l}}
$$

where $\tau^{E}$ represents the maximal area which could be occupied by activities of type $E$, and $\gamma^{l}$ and $\gamma^{k}$ indicate the area occupied per unit of employment in activity $l(l=1, \ldots 4)$ and per unit of resident $(k=1,2)$. 
All these factors are assumed to combine their effects in a multiplicative way. The formulation for the global attractiveness of a zone $j$ is then:

$$
A_{j}=\left[\frac{1+\rho^{E} S_{j}^{E}\left(1-\psi^{E} S_{j}^{E}\right)}{1+\alpha_{j}^{E} \phi^{E}} \cdot \frac{\tau^{E}}{\tau^{E}+\sum_{k} \gamma^{k} x_{j}^{k}+\sum_{l} \gamma^{l} S_{j}^{l}}\right]^{C o}
$$

(iv) Sensitivity to differences in attractiveness. In the above expression, the $\mathrm{Co}$ parameter depicts the degree of unanimity in the response of the urban actors to the attractiveness of the zones. A high $C o$ value reflects a situation where all the actors are well informed and react with unanimity. In such a case, the activities will tend to concentrate in the most attractive zone. On the other hand, a low value expresses a large elasticity in response to the differences in attractiveness from one zone to the other.

\section{Service Activities}

The two types of service activities are induced by the population of the agglomeration itself. The short-range activities correspond to services which are always used by the nearby residents, whereas medium-range services may attract more distant customers, for instance, the largest commercial centers.

Their evolutions are described by equations (4) and (5):

$$
\frac{d S_{j}^{u}}{d t}=\varepsilon^{u} S_{j}^{u}\left[1-\frac{S_{j}^{u}}{\sum_{j^{\prime}}\left(\sum_{k} \beta_{k}^{u} x_{j^{\prime}}^{k} \frac{A_{j j^{\prime}}{ }^{C o}}{\sum_{j^{\prime \prime}} A_{j^{\prime} j^{\prime \prime}} C^{\prime \prime}}\right)}\right]
$$

with

$$
\begin{aligned}
& A_{j j^{\prime}}=\left[\frac{1+\rho^{u} S_{j}^{u}\left(1-\psi^{u} S_{j}^{u}\right)}{1+\phi^{u} d_{j j^{\prime}}} \cdot \frac{\tau^{u}}{\tau^{u}+\sum_{k} \gamma^{k} x_{j}^{k}+\sum_{l} \gamma^{l} S_{j}^{l}}\right] \\
& u=1=\text { short-range activities. } \\
& u=2=\text { medium-range activities. }
\end{aligned}
$$

where $S_{j}^{u}$ is the number of jobs in activity $u$ in zone $j$.

The general structure of these equations is the same as for exporting activities nd we will only clarify the two points which are different. In the formulation of the potential of each zone $j$, the demand is induced by the resident population of each group $x^{k}$ according to a multiplier $\beta_{k}^{u}$. So $\sum \beta_{k}^{u} x_{j^{\prime}}^{k}$, represents the number of jobs induced by the resident population $(k=1=$ bluecollar; $k=2=$ whitecollar) of zone $j^{\prime}$. The location of these jobs in a zone $j$ depends on the relative 
attractiveness

$$
\frac{A_{j j^{\prime}}}{\sum_{j^{\prime \prime}} A_{j^{\prime} j^{\prime \prime}}}
$$

of zone $j$ for consumers of the zone $j^{\prime}$. Then, the term

$$
\sum_{j^{\prime}} \sum_{k} \beta_{k}^{u} x_{j}^{k} \frac{A_{j j^{\prime}}}{\sum_{j^{\prime \prime}} A_{j^{\prime} j^{\prime \prime}}}
$$

represents the total service employment of type $u$ induced in zone $j$ by the consumers of all zones in the agglomeration. The attractiveness is measured for each pair of zones $\left(j, j^{\prime}\right)$. It has the same general form as that of exporting activities, but the effect of accessibility is replaced by the impact of the distance between zones $j$ and $j^{\prime}$ : there is a distance decay function $1 /\left(1+\phi^{u} d_{j j^{\prime}}\right)$, where $d_{j j^{\prime}}$ is the distance from $j^{\prime}$ to $j$ and $\phi^{u}$ a measure of the deterrence effect of the distance for services of type $u$.

\section{The Resident Population}

The population is divided into two groups, blue- and white-collar. Their evolutions are described by equations (6) and (7):

$$
\frac{d x_{j}^{k}}{d t}=\eta^{k} x_{j}^{k}\left[1-\frac{x_{j}^{k}}{\sum_{j^{\prime}}\left(\sum_{l} \mathrm{Z}^{k l} S_{j^{\prime}}^{l} \frac{R_{j j^{\prime}}}{\sum_{j^{\prime \prime}} R_{j^{\prime \prime} j^{\prime}}}\right)}\right]
$$

with

$$
R_{j j^{\prime}}=\left[\frac{\nu^{k}\left(1+\sigma^{k} x_{j}^{k}\right)}{\nu^{k}+\sum_{k^{\prime}} \gamma^{k^{\prime}} x_{j}^{k^{\prime}}+\sum_{l} \gamma^{l} S_{j}^{l}} e^{-b^{k} d_{j j^{\prime}}}\right]
$$

where $x_{j}^{k}$ is the number of residents of type $k$ in zone $j$.

The residential potential of a zone $j$ depends on the distribution of employment in the agglomeration. $S_{j^{\prime}}^{l}$ is the number of jobs of type 1 in zone $j^{\prime}$, and $Z^{k l}$ is a parameter expressing the proportion of jobs of category $k$ (blue- or white-collar) in sector 1 . Then the product $S_{j}^{l} Z^{k l}$ gives the number of jobs of category $k$ in the activity 1 in the zone $j^{\prime}$. People working in a zone $j^{\prime}$ reside in a zone $j$ according to its relative residential attractiveness $R_{j j^{\prime}} / \sum_{j^{\prime \prime}} R_{j^{\prime} j^{\prime \prime}}$. In addition to a constraint of available space, this residential attractiveness varies with a parameter $\sigma^{k}$ measuring gregarious tendencies among social group $k$ and with the distance $d_{j j^{\prime}}$ according to a distance decay function $e^{-b_{d i j^{\prime}}^{k}}$ where $b^{k}$ measures the sensitivity of the social group $k$ to commuting distances. 


\section{APPLICATION OF THE MODEL TO THE AGGLOMERATION OF ROUEN}

In order to test the ability of such a model to simulate an observed urban evolution, we need detailed and spatially disaggregated data about the composition and location of the labor force in a city over a long period of time. Such data is available in France from the censuses (1954, 1962, 1968 and 1975) at the geographical level of the commune. To have a sufficient number of spatial units we choose a large agglomeration. Rouen is a large urban area (about 400,000 inhabitants), subdivided into 17 "communes". The "commune" of Rouen is centrally located and has about ten times as many jobs and residents as any other commune of the agglomeration.

For each of the 17 communes, we collected comparable data for four census years. Labor force is registered at the work-place and had to be divided into four types of economic activity. From existing classifications it is possible to calculate only the number of people employed in industry. To distinguish three levels (local, regional, and exporting) among tertiary activities, we applied the minimum requirement technique to that data. The two categories of resident population were derived from census data by grouping all laborers as "blue-collar" and all others as "white-collar".

Distances between the 17 zones of the agglomeration have been calculated as straight-line geographical distances. Indeed, it has been shown (Guermond 1983) that this distance gave better results for classical interaction models in Rouen than any travel-time distance. Although some parameters (for example, the demand of export activities) were estimated from empirical data, most of them were fitted by calibration.

After a brief presentation of the agglomeration of Rouen, the results of the calibration are analyzed.

\section{Evolution of the Agglomeration Between 1954 and 1975}

Figure 1 illustrates the zoning of the agglomeration; the river Seine crosses it and is a main axis for communication and a decisive factor in the location of industry. Figure 1 also shows the heterogeneity of the distribution of activities and of resident population as well as the differences in their total growth from one commune to another. Three rings can be distinguished:

1. The center and the neighboring communes with very slow growth rate. Saturation phenomenon explain this recent stagnation that can be observed in all large agglomerations.

2. A set of rapidly growing communes situated around the oldest urbanized areas. On the left bank of the Seine, these communes had important industrial development along the river.

3. Communes of the largest periphery had smaller rates of growth. They are situated in the old industrial valleys in the northern and eastern part and in less developed areas of the south.

The social structure is also very different from one zone to another. For example, 16 percent of blue-collar workers are in zone 4 , but 60 percent in zone 17 . The spatial segregation has been exacerbated since 1954. The population of the right bank has a higher proportion of white-collar workers than the left bank where blue-collar workers form the main social group. Figure 2 shows the detailed curve of evolution for each variable in each zone from 1954 to 1975 . A very large variety of individual communal trajectories will have to be simulated by the model.

\section{Calibration}

Because of the large number of parameters and of the numerous interdependencies between the variables, the calibration of such a complex model is 

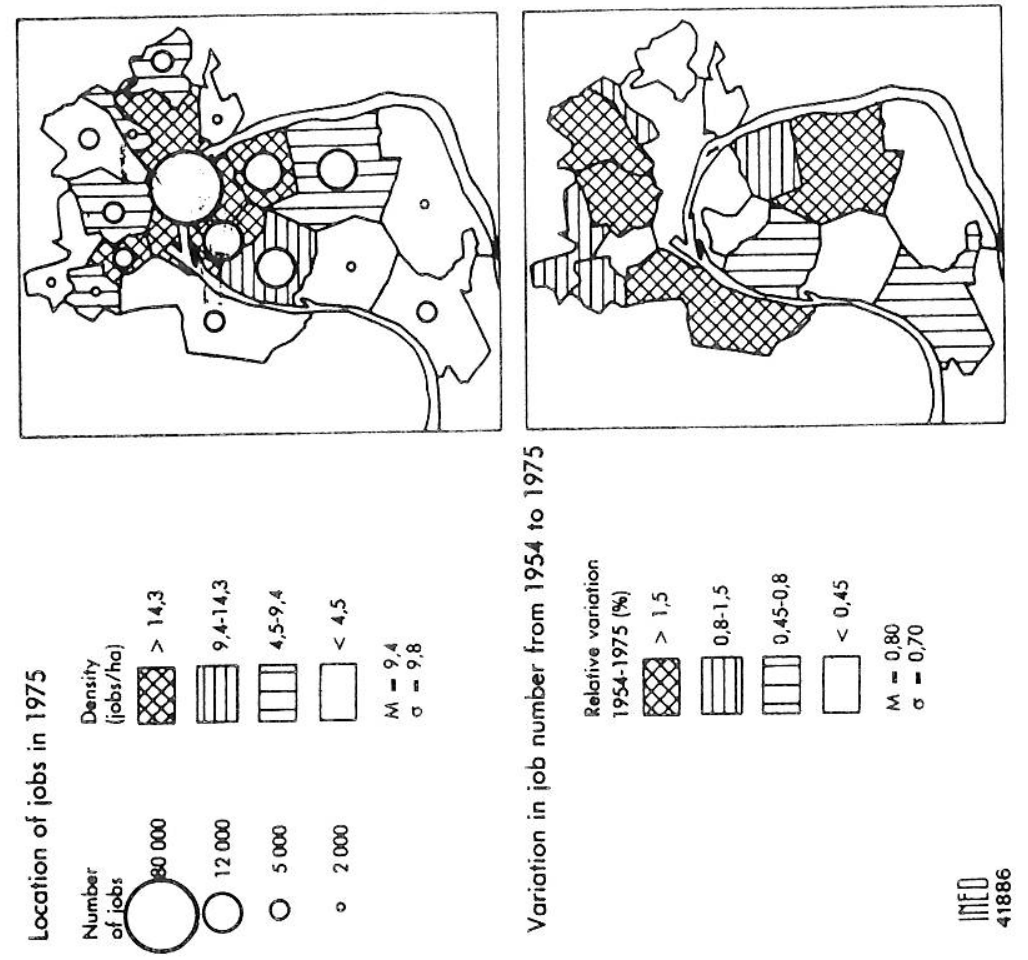

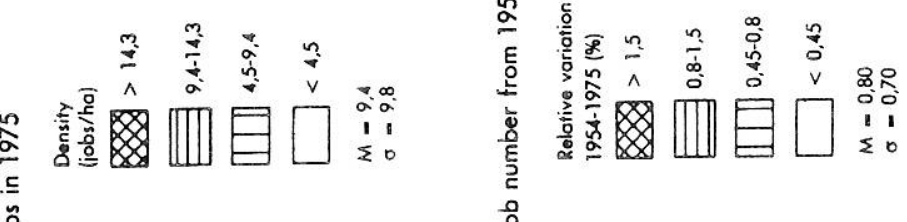
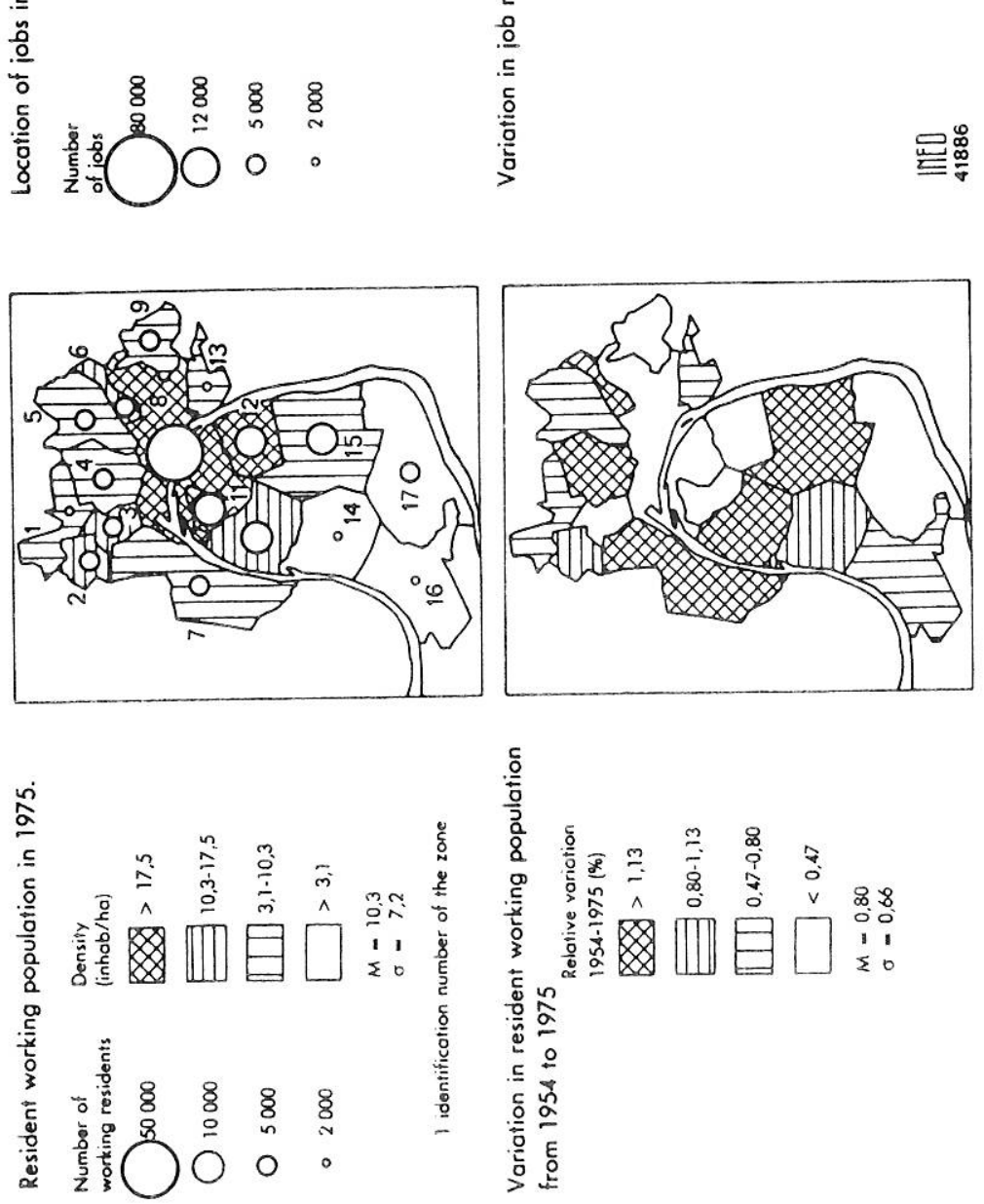

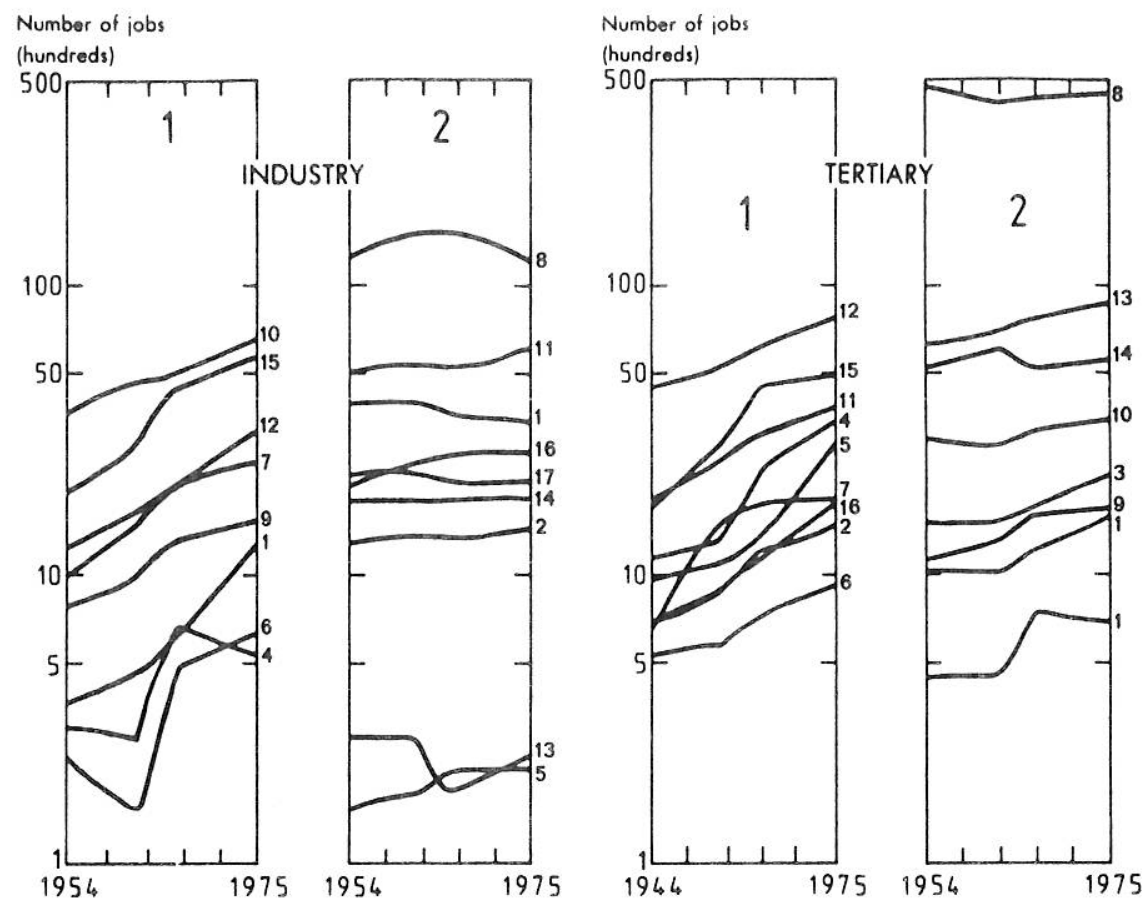

Number of residents

(thousands)

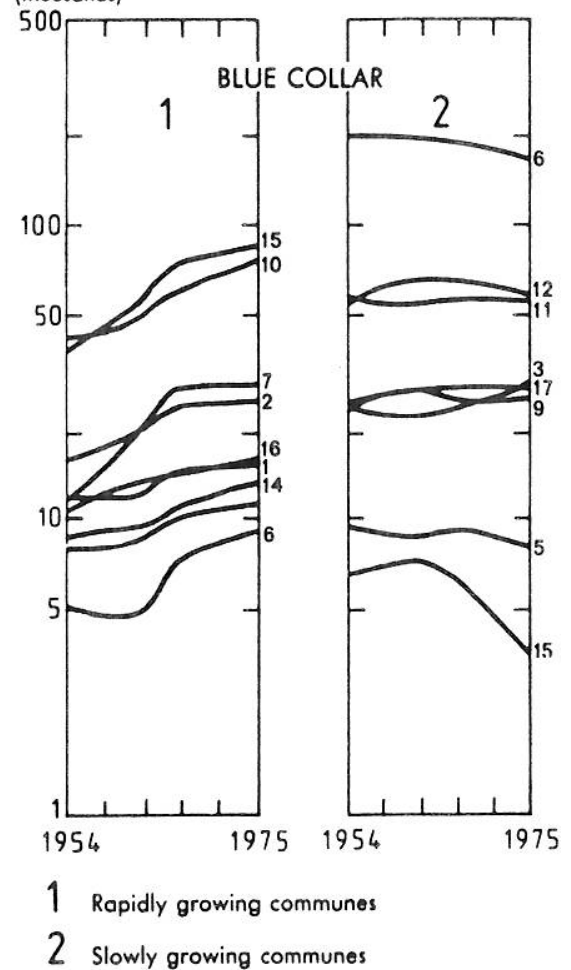

Number of residents

(thousonds)

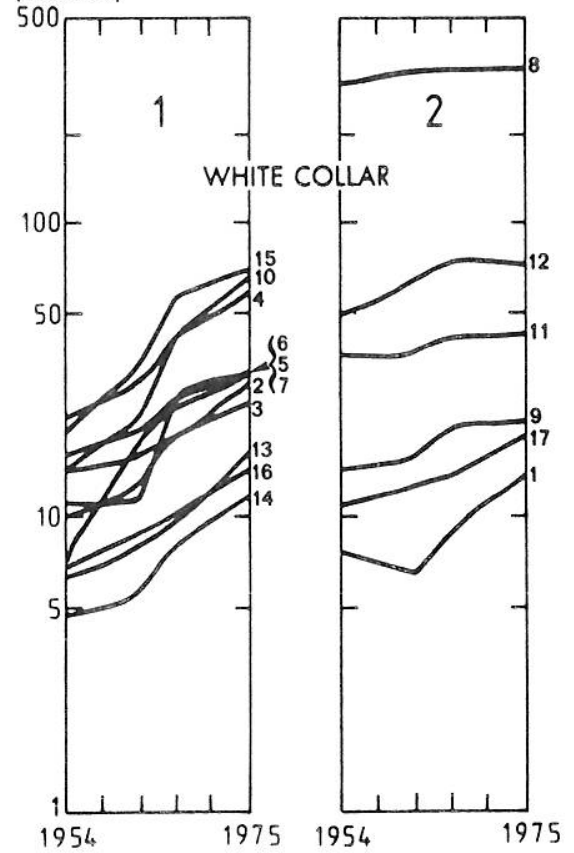

1 Rapidly growing communes

$\underset{41986}{\operatorname{lnF}}$

FIG. 2 
complicated. Automatic calibration methods are not suited to such models so we utilized an experimental approach. The model has a high propensity to produce bifurcations. Among the set of values that we used for the parameters, many determined unrealistic changes in the spatial configuration of our urban area. More frequent patterns were a total concentration of employment and resident population in the center, or in two or three peripheral subcenters, or a complete dispersion with a uniform distribution over all the urban zones. The problem then was to find a set of parameters which could produce smoother dynamics. It is important to note that the existence and uniqueness of the solution cannot be proved. However, after the large number of simulations (about 300), it seems very unlikely that a completely different set of parameters would reproduce the observed evolutions as well as the ones we obtained.

The analysis of the residuals, i.e., the differences between the observed situation in 1975 and the calibrated one, is useful in exemplifying the capability and limitations of such a model. Since the location of industry and tertiary exporting activity is calibrated by the means of one parameter for each zone (the $\alpha_{j}$ parameter, standing for accessibility), the evolution of these two variables is accurately simulated and residuals are negligible. Figure 3 shows the residuals for four variables: blue-collar and white-collar, and the short- and medium-range tertiary activities. They underline the internal coherence of the model: if the resident population in a zone is overestimated by the model, then the induced short-range activities are also overestimated in the same zone.

Three types of communes correspond to different levels of compatibility with the model.

(i) Communes with Low Residuals. The evolutions of the commune of Rouen itself, the communes surrounding the center, the two communes of the southern part, and most of the communes of the northwestern part are quite well reproduced by the model for most of the variables. These results occur even in heterogeneous situations with significant variations in size (the size of these zones varies from the largest [the center] to the smallest [zone 6]); location (from a central position to the extreme southern and northwestern parts of the agglomeration); and evolution (some are stagnating [the center and zone 17] and others are growing very rapidly [zones 2 and 16].

(ii) A Group of Underestimated Communes. The model has systematically underestimated the values of two communes (the zones 10 and 15). These zones had a very large growth, especially in their residential population. The simulation actually reproduces growth for these variables but it is insufficient in comparison with the actual growth (a simulated increase of 40 percent for the population between 1954 and 1975 whereas the actual increase was 154 percent). Two factors explain this deficiency of the model. 1, the very large size of these communes is not sufficiently taken into account by what is termed "space availability" in the measure of attractiveness, and 2, large housing programs are mostly responsible for the rapid growth of these communes. The availability of space had surely been an important factor in their location, but also the low price of land which is not taken into account by the model.

(iii) A Group of Overestimated Communes. Some of the zones situated north and east of the center and one commune on the left bank are overestimated for all the variables. Except for the one on the left bank, these communes are all situated on a plateau dominating the city and this situation produces some constraints that the model does not take into account. The access to 

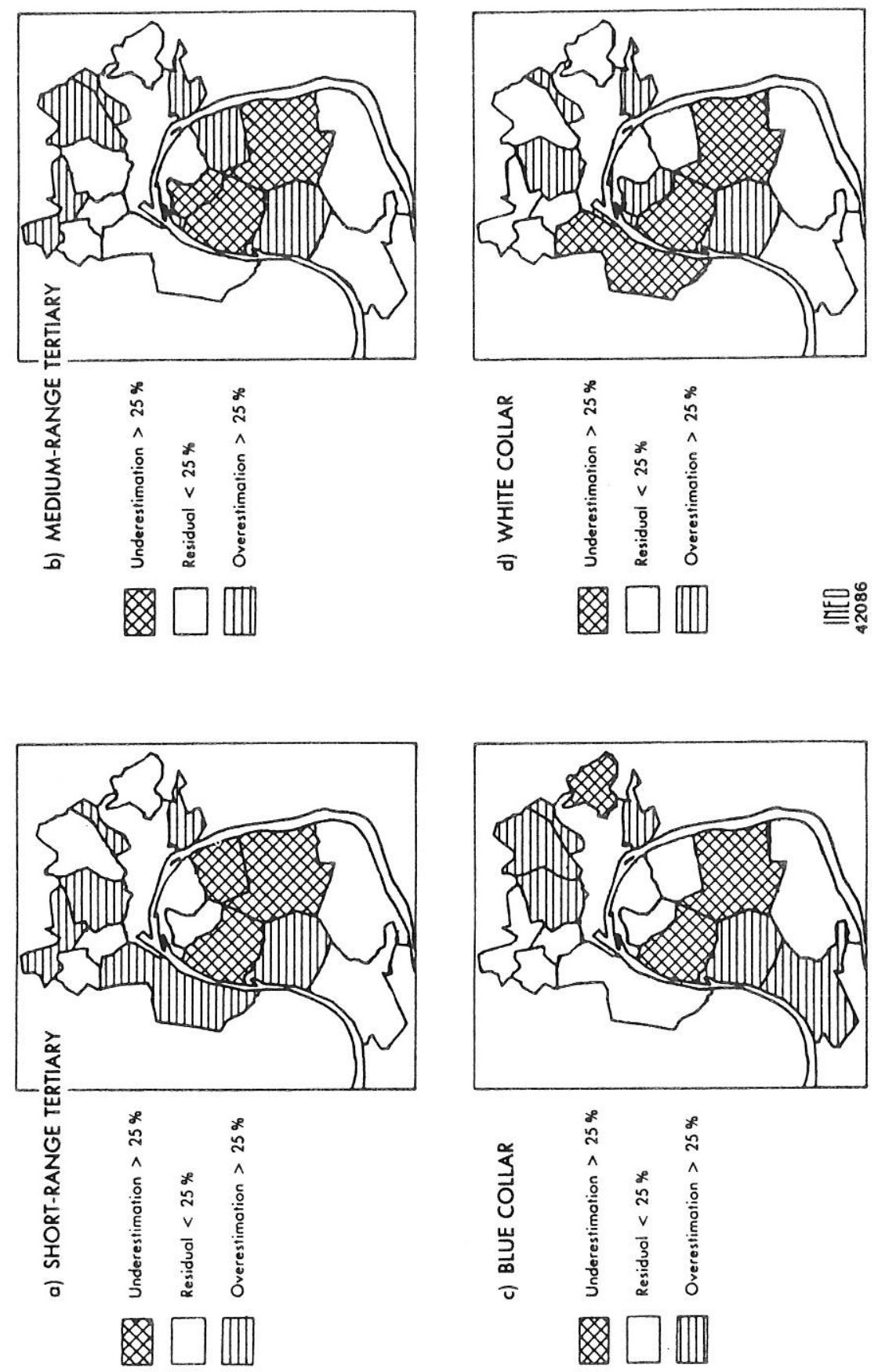
the plateau is more difficult than to other places and the geographical distance used in the model is not suited to this steep relief. The cost of construction is higher in these areas because of the steep slopes, although the cliffs are attractive locations because of the beauty of the site and the absence of pollution. There are mainly villas in these zones, constructed on big plots and, of course, reserved for wealthy populations. These remarks reflect the lack of a land price constraint in the model.

\section{COMPARATIVE ANALYSIS OF RESULTS FOR THE FOUR AGGLOMERATIONS}

The four agglomerations of Bordeaux, Nantes, Rouen, and Strasbourg range from the 5th to the 12th rank in the French urban hierarchy, ranging from 612,000 to 365,000 inhabitants in 1975. The agglomerations are divided into 15 to 23 communes. They all have diversified activities; 24 to 33 percent of employment is in industry, 35 to 43 percent is blue-collar. They differ more in the relative weights of their main subdivisions (the "commune-centers"): has a very high population Strasbourg's and the concentration of residential population in their communecenters is more pronounced in both Nantes and Strasbourg than in Rouen or Bordeaux.

The hypothesis of the model, that the spatial redistribution of employment and resident population in the cities is explained by general modes of interaction, holds rather well. A simulated calibration was possible in each case, and was easier than in the case of Rouen, because of greater experience with the model. However, the residuals between observed and simulated evolution are subject to the same general interpretation as in Rouen. They reveal either specific properties of the site in some communes (the relief in the north of the Rouen agglomeration, the international boundary in Strasbourg), or large planned housing programs. Naturally, a finer analysis of residuals emphasizes information about particular evolutions in given areas.

The values which were found for the parameters are of the same scale (Table 1). However, they can not be used directly to qualify the comparative dynamics of each agglomeration, since many of them depend on the size of the initial variables. To make the comparison easier, indices have been calculated as measures of differential attractiveness between the zones in each agglomeration. They were designed to show the respective shares of agglomeration effects, that is, accessibility and availability of space, in these differences in attractiveness. The index $R$ is a ratio between the corresponding components in the first and the second value for the attractiveness function (the highest value generally corresponds to the center). The index $D$ replaces $R$ in the cases of service activities and resident population for measuring the role of accessibility in the attractiveness. $D_{1}$ is the ratio between the effect of a distance of one kilometer (which is the average distance inside one zone), and the effect of a distance of two and a half kilometers (which is the average distance between two contiguous communes); $D_{2}$ is the ratio between the effects of one-kilometer and five-kilometer distances. The index $M$ is a ratio between the highest and the lowest values for the attractiveness and is used to measure a differential effect in availability of space.

Table 2 allows a comparison of the relative importance of each of the three components: agglomeration effects, accessibility, and availability of space, in the dynamics of the four agglomerations. These measures underline the importance of centrality and accessibility, with a minor role devoted to space availability. The agglomeration economies appear then as the essential explanatory factor for the evolving geographical distribution of jobs and populations in the city. This expresses a certain inertia of the system, the persistency of locations. Basic tertiary activities 


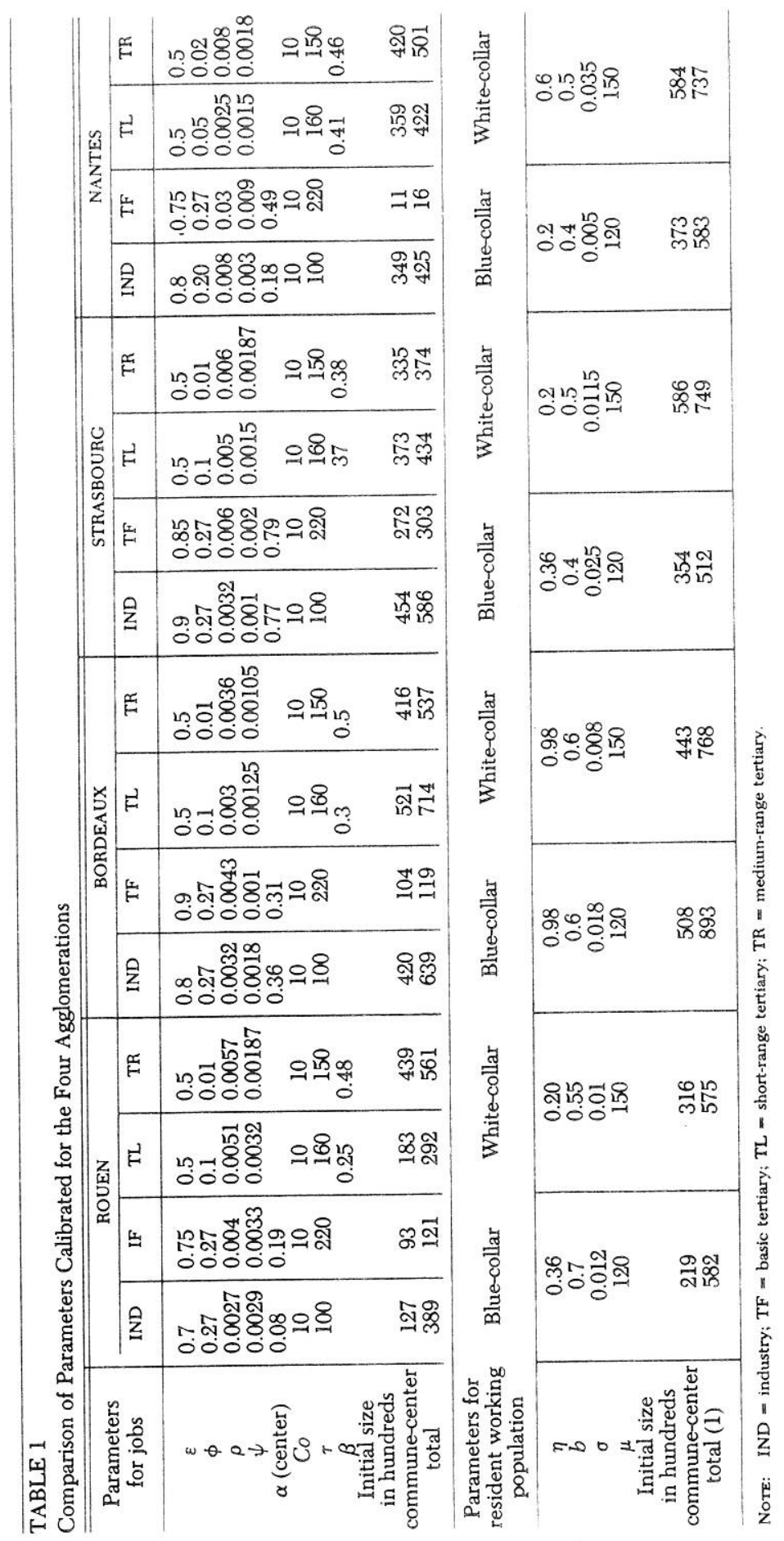




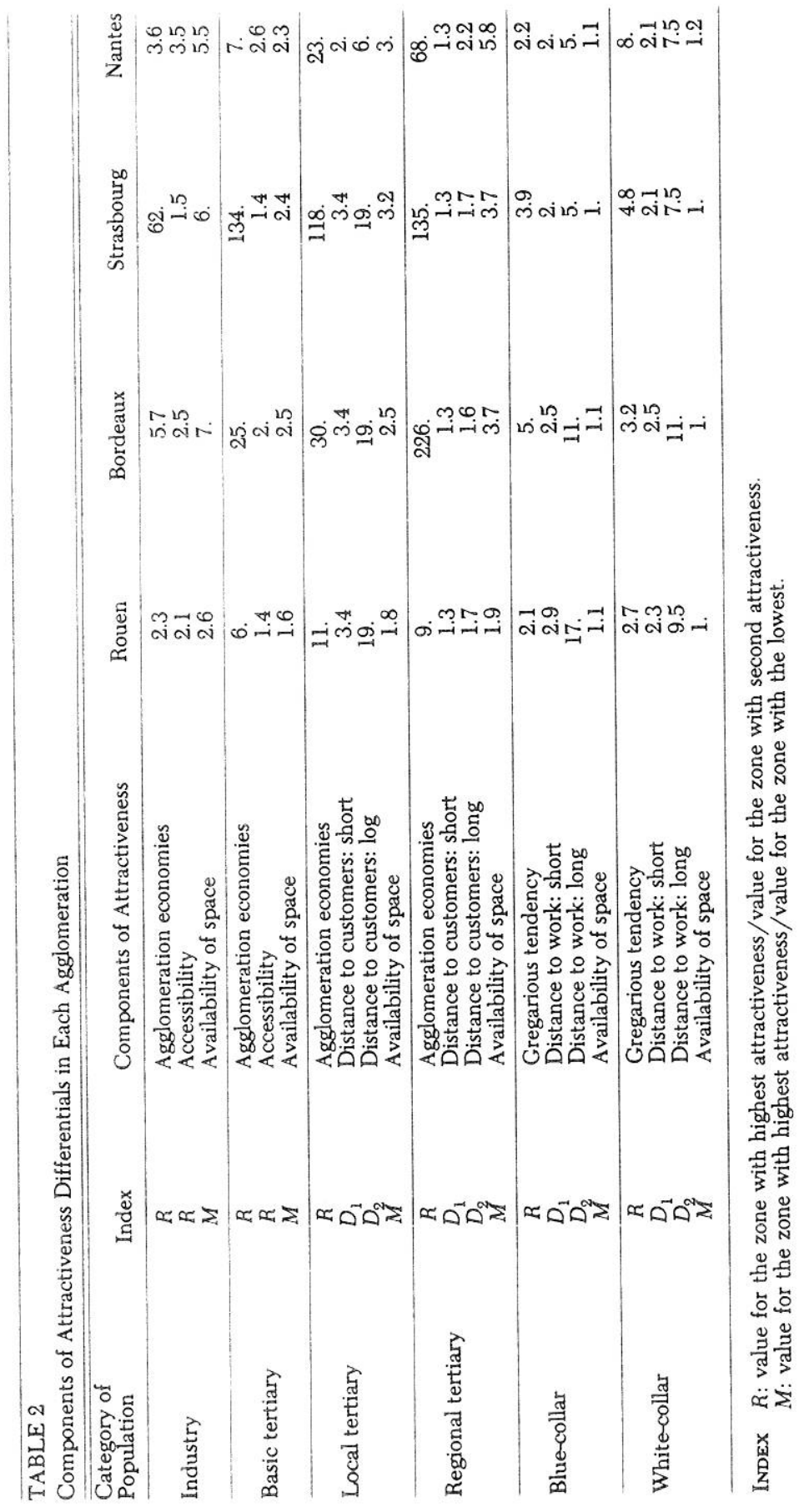


and regional tertiary activities are extreme cases for which this is almost the only effective factor. L_ocation constraints have stronger effects for industry, local services, and resident populations. In the latter case, distance appears less significant than the propensity to agglomerate when the working place and the residence are located in the same commune or in neighboring ones (see values corresponding to $\left.D_{1}\right)$. But when the commuting distance is larger, it becomes the most important factor in differentiating the attractiveness of the communes ( $D_{2}$ values). The availability of space plays a significant role only for industrial activities and is quite negligible in the case of resident population.

These indices also summarize and allow us to compare the spatial evolution of the four agglomerations over the last thirty years. For instance, the dominant effect of centrality appears in Strasbourg, but also in Bordeaux for the tertiary sector and in Nantes for services activities. The differences in accessibility play a greater role in Bordeaux and especially in Nantes, where there is a lack of communication between the center and the other parts of the agglomeration. Constraints due to the availability of space are almost nonexistent in Rouen, where there are large opportunities for industrial establishments on the wide flat left bank of the Seine river. Space constraints are more important in the other cities where potential locations for industry are less numerous.

\section{CONCLUSION}

Facing the theoretical power of urban dynamic models on the one hand, and the scarcity and novelty of their applications on the other hand, what can be said from a first exploratory use of such a model?

The main conceptual interest of these types of models is their ability to simulate qualitative changes in an urban spatial structure. They can replicate discontinuities in the evolution of the spatial pattern of population and activities in one single city; they also show that the same rules of urban dynamics may lead to various forms of spatial organization in urban areas, according to different values of their parameters.

Moreover, our application of Allen's intraurban model to four large French urban cities has illustrated its ability to reproduce the observed evolution of real-world towns. The global spatial dynamics of the agglomerations have been rather accurately simulated, as well as a large variety of the trajectories of the urban subareas. This confirms the validity of general hypothesis of the model, which explains local dynamics in a city by general mechanisms of spatial evolution and interaction. It seems also that the mechanisms which have been introduced in the model are relevant and complete, with regard to the level of explanation and of spatial disaggregation being considered.

The performances of the model could be improved by introducing an expression of the cost of land in the equations. But other difficulties which were encountered in the application are less easily surmountable. The calibration of the evolution of a town remains difficult because of the bifurcational properties of the equations. The comparison of the dynamics of several towns is not easy, either, since the values of the parameters cannot be standardized and are dependent on the size of the areas under study. Those values reflect then not only a particular spatial dynamics but also the type of spatial disaggregation that is used for each town.

Despite those difficulties in application, this model remains a useful tool for testing various hypotheses about the evolution of an urban system. For a better evaluation of its specifications, the results provided by this model could be compared with others, for instance, the Wilson model, used by Lombardo and Rabino (1983) for Rome. This will be the next step in our experimentation. 


\section{LITERATURE CITED}

Allen, P. (1978) "Dynamique des Centres Urbains." Sciences et Techniques Avril, 50, 15-19.

Allen, P., and M. Sanglier (1981). "Urban Evolution, Self-organization and Decision Making." Environment and Planning 13, 169-183.

Alle P. M. Sanglier, F. Boon, J. L. Deneubourg, and A. De Palma (1981). "Models of Urban Settlement and Structure as Dynamic Self-organizing Systems." Washington, D. C.: Department of Transportation.

Allen, P., G. Engelen, and M. Sanglier (1984). "Self-organizing Systems and the Laws of Socio-economic Geography." Brussels Working Papers on Spatial Analysis, Series A, 4.

Griffith, D. A., and A. C. Lea, eds. (1984). Evolving Geographical Structures. NATO Advanced Institute Series. Den Haag: Martinus Nijhoff.

Guermond, Y. (1983). “Modélisation des Migrations Alternantes.” L'Espace Géographique 3, 215-222. Haag, G., and D. S. Dendrinos (1983). "Toward a Stochastic Dynamical Theory of Location: A Non-Linear Migration Process." Geographical Analysis 15, 3, 269-286.

Lombardo, S., and G. Rabino (1983). Non Linear Dynamic Models for Spatial Interaction: The Result of Some Empirical Experiments. Poitiers: Congrès Européen de l'Association de Science Régionale. Lowry, I. (1964). A Model of Metropolis. RM-4035 RC. Santa Monica: Rand Corporation.

Paelinck, J. (1980). "Dynamic Urban Growth Models." Papers of the Regional Science Association 24, 25-37.

Pumain, D., and T. Saint-Julien (1978). Les Dimensions du Changement Urbain. Mémoires et Documents de Géographie. Paris: CNRS.

Pumain, D., T. Saint-Julien, and L. Sanders (1986) "Urban Dynamics of Some French Cities." European Journal of Operational Research, special issue. 125-135

(1984). "Vers une Modélisation de la Dynamique Intra-urbaine." L'espace Géographique 2,

Pumain, D., L. Sanders, and T. Saint-Julien (1985). Dynamique des Systèmes et Milieu Urbain. Paris: C. N. R. S. Rapport pour le PIREN.

Sanders, L. (1984). Interaction spatiale et Modélisation Dynamique, Application aux Systèmes Urbains. Université Paris VII, Thèse de 3ème cycle.

Wilson, A. G. (1984). "Making Urban Models More Realistic: Some Strategies for Future Research." Environment and Planning 16, 1419-32.

\section{An Empirical Analysis of Urban Activity Patterns by Wilfred W. Recker, Michael G. McNally, and Gregory S. Root \\ INTRODUCTION}

This paper presents an empirical framework to assess the relationships between activities, constraints, and the manner in which they are channeled into particular time-space paths through the analysis of daily travel/activity patterns. The use of activity patterns as a surrogate for travel behavior and travel patterns is consistent with the position that trip making can be better understood when trips and

That this research was supported, in part, by a grant from the U.S. Department of Transportation is gratefully acknowledged.

Wilfred W. Recker is professor and director of the Institute of Transportation Studies, University of California, Irvine. Michael G. McNally is assistant professor, University of Southern California, Los Angeles. Gregory S. Root is assistant professor, University of South Florida.

Geographical Analysis, Vol. 19, No. 2 (April 1987) (c) 1987 Ohio State University Press Submitted 10/84. Revised version accepted 10/86. 